\title{
Cutting force prediction considering force- deflection coupling in five-axis milling with fillet-end cutter
}

\section{Xianyin Duan}

Wuhan University of Science and TechnologyWuhan University of Science and Technology

\section{Lantao Li}

Wuhan University of Science and Technology

Chen Chen ( $\nabla$ chenchen_1014@foxmail.com)

Huazhong University of Science and Technology

Sheng Yu

Huazhong University of Science and Technology

Zerun Zhu

Huazhong University of Science and Technology

\section{Fangyu Peng}

Huazhong University of Science and Technology

\section{Research Article}

Keywords: Cutting force, Force-deflection coupling, Five-axis milling, Fillet-end cutter

Posted Date: August 9th, 2021

DOI: https://doi.org/10.21203/rs.3.rs-766959/v1

License: (c) (1) This work is licensed under a Creative Commons Attribution 4.0 International License. Read Full License

Version of Record: A version of this preprint was published at The International Journal of Advanced Manufacturing Technology on January 24th, 2022. See the published version at https://doi.org/10.1007/s00170-022-08654-x. 


\title{
Cutting force prediction considering force-deflection coupling in five-axis milling with fillet-end cutter
}

\author{
Xianyin Duan ${ }^{1} \cdot$ Lantao ${ }^{1} \cdot$ Chen Chen ${ }^{2, *} \cdot$ Sheng $\mathrm{Yu}^{3} \cdot$ Zerun $\mathrm{Zhu}^{2} \cdot$ Fangyu Peng ${ }^{2}$ \\ ${ }^{1}$ Hubei Key Laboratory of Mechanical Transmission and Manufacturing Engineering, \\ Wuhan University of Science and Technology, Wuhan, 430081, Hubei, China \\ ${ }^{2}$ School of Mechanical Science and Engineering, \\ Huazhong University of Science and Technology, Wuhan, 430074, Hubei, China \\ ${ }^{3}$ Key Laboratory of Metallurgical Equipment and Control Technology, Ministry of Education, \\ Wuhan University of Science and Technology, Wuhan, 430081, Hubei, China
}

\begin{abstract}
With the increasing demand for higher quality and performance of equipment and assembly in aerospace, shipbuilding, medical and other fields, the machining accuracy of parts is facing higher requirements. It is particularly important to predict the cutting force accurately, which is the main physical quantity in the machining process and basis of process inspection and quality control. In this paper, the cutting force model in five-axis milling with fillet-end cutter is proposed, which reveals the law of force-deflection coupling. Firstly, the initial cutter deflection model induced by the ideal cutting force ignoring the effect of deflection is built based on analysis of the geometric characteristics of fillet-end cutter. Then the undeformed chip thickness model is educed considering the cutter posture and cutter deflection. Further, the iterative method is utilized to resolve the coupling relationship between cutter deflection and cutting force. Finally, the cutting force model under forcedeflection coupling is established for achieving more accurate prediction. To verify the effectiveness of the proposed cutting force model, the milling experiment is carried out on a five-axis milling center. The measured cutting force values are utilized to inspect the accuracy of prediction models considering and not considering force-deflection coupling respectively. The results show that the proposed method could improve the prediction accuracy of cutting force, which show the effectiveness of taking force-deflection coupling law into consideration clearly. The influence of cutter posture on cutting force is analyzed using the proposed cutting force model. The cutting force decreases with the increasing of lead angle or tilt angle, and the influence of tilt angle is greater than that of lead angle under experimental conditions of five-axis milling using the set process parameters.
\end{abstract}

Keywords: Cutting force; Force-deflection coupling; Five-axis milling; Fillet-end cutter.

\section{Introduction}

With the rapid development of the industry such as aerospace, shipbuilding equipment medical, etc., the requirements of equipment service performance are improved, which puts forward an urgent demand for the machining accuracy of key parts. These parts usually have complex free-form surface with characteristics of nonlinear contour, large surface curvature changes and overlapping machining

\footnotetext{
* Corresponding author Chen Chen at: B424, Advanced manufacturing building, Huazhong University of Science \& Technology (HUST), 1037 Luoyu Road, Wuhan, China. Area code: 430074. Tel.: +86-150 72401849.

E-mail addresses: chenchen_1014@foxmail.com (Chen Chen), xyduan@wust.edu.cn (Xianyin Duan), lilantao98@foxmail.com (Lantao Li)
} 
features. For example, the nonlinear multi-blade propeller applied in underwater ships is a typical difficult-to-machine part which has the characteristics of complex blade shape and narrow flow channel and limits that the cutter must have a slender feature to match narrow feasible space. The cutter deflection produced under action of cutting force becomes an issue that cannot be ignored as the slender cutter has poor stiffness. The taking of deflection into account makes the accurate prediction of cutting force becomes much more difficult because the cutter-workpiece engagement becomes more complex. The free-form surface of the part makes the cutter posture change in five axis machining, so the lead angle and tilt angle should be considered in the cutting force model. Martellotti $\mathrm{M} \mathrm{E}^{[1]}$ proposed to discretize the cutting edge part as the cutting edge element and defined the cutting force of the element as the product of load area of the chip element and unit cutting force coefficient, known as the mechanical model of cutting force widely used by later scholars. Then Malekian $\mathrm{M}^{[2]}$ established the minimum chip thickness model initiatively, which promoted the development of mechanical model. Budak $\mathrm{E}^{[3]}$ presented models for 5-axis milling process geometry, cutting force and stability. Based on the classical cutting force theory of predecessors, there has been a significant development in the cutting force model.

Scholars combined specific conditions to establish cutting force model. Xuewei $\mathrm{Z}^{[4]}$ proposed a new stochastic model of cutting force in the milling process of ceramic matrix composites. Qinghua $\mathrm{S}^{[5]}$ established a comprehensive generalized mechanical model to predict the cutting force in the five-axis milling process and verified that both the instantaneous force and the axial force component of each tooth could be well predicted using the model. Lin $\mathrm{Z}^{[6]}$ proposed a semi-analytical model to estimate the cutting force of NAK80 steel micro ball end milling cutter considering the change of cutting edge wear and related nonlinear process characteristics. Hui $\mathrm{W}^{[7]}$ established the mechanism model of cutting forces in the feed direction of CFRP composite end face grinding with horizontal ultrasonic vibration, and established a mechanical model based on toughness model. Salehi $\mathrm{M}^{[8]}$ proposed cutting forces prediction using Bayesian inference (MCMC simulation) for the Merchant and Kienzle force models. John $\mathrm{M}^{[9]}$ developed a new energy dissipation mechanism, improving the previously derived steady-state cutting force analysis model, to improve the predictive ability of high blade cutting conditions. Zhoulong $\mathrm{L}^{[10]}$ proposed an improved machining mechanism model of fiveaxis flat end mill, which can accurately predict the cutting force by combining the cutting effect of side and bottom. Jian $\mathrm{W}^{[11]}$ proposed an improved force prediction model in which the constants could be calibrated based on particle swarm optimization algorithm. Lexiang $\mathrm{W}^{[12]}$ proposed an analytical method to investigate the material removal mechanism in rotary milling to predict undeformed chip geometry, material removal rate (MRR), cutting forces, and shape errors. Ozturk E ${ }^{[13]}$ investigated the effects of lead and tilt angles on cutting forces, torque, form errors and stability through modelling and verified by experimental results. Lazoglu ${ }^{[14]}$ developed mathematical model for five-axis milling mechanics for any given solid model of parts with complex free form surfaces. Tuysuz $\mathrm{O}^{[15]}$ presented a mechanics model that predicts the cutting forces in feed, normal and axial directions by modeling the chip thickness distribution and cutting and indentation mechanics. Wojciechowski. $S^{[16]}$ focused on the prediction of cutting forces during micro end milling using a novel approach that considered the chip thickness accumulation phenomenon. Dongming $\mathrm{G}^{\text {[17] }}$ presented a new mechanistic model of cutting forces based on tool motion analysis. 
Different cutting force models were built in different conditions. The specific coefficients in the model were related to the actual working conditions.

Above studies promoted the development of cutting force model. By studying the points such as the cutting edge element, the undeformed chip thickness model and the cutter geometry, it made a great contribution to the prediction of cutting force. However, only single influence factor was considered in above studies, and the analysis to be carried out were not comprehensive enough.

In the real machining process, under the impact of cutter runout, the actual cutter rotary surface and swept envelope surface are no longer consistent with the nominal ones. Cutter runout would make the workpiece bending deflection and vibration during processing and affect the quality of the workpiece processing. For this reason, cutter runout was considered by many scholars when studying cutting force. Niu $\mathrm{J}^{[18]}$ studied the combined effects of cutting parameters, cutter geometry and runout on regenerative chatter behavior. Wei Z C ${ }^{[19-21]}$ comprehensively considered the influence of instantaneous chip thickness and cutter runout on cutting force with analytical algorithm. Zhu $\mathrm{K}^{\text {[22] }}$ proposed an improved model of instantaneous cutting force per tooth by considering the cutter runout effect in five-axis milling, which could accurately describe the instantaneous force per tooth under the influence of cutter runout. Xiubing $\mathrm{J}^{[23]}$ studied the effect of elastic recovery and cutter runout on cutting force and established a mechanical model to accurately predict cutting force. Based on an improved high-order Taylor formula analysis method, Zhang $\mathrm{X}^{[24]}$ established an accurate calculation model for the instantaneous engagement process of cutter-workpiece in five-axis ball end milling by combining the cutter positioning, actual cutter runout and cutter movement process. Zhoulong L [25] studied the cutter runout phenomenon in the cutting process and proposed an accurate method to calculate the cutter-workpiece engagement boundary in five-axis milling. Cutter runout is one of the important factors affecting the cutting force model, which has been studied by many scholars. However, besides the cutter runout, cutter deflection would occur in the machining process. Thus, the influence of cutter deflection on the cutting force model is also essential.

The influence of cutter deflection on cutting force model could not be ignored. Cutter deflection has become a hot topic in cutting force research. Many scholars had explored the relationship between cutter deflection and cutting force. Xianyin $\mathrm{D}^{[26]}$ studied a non-geometric constraint, the static deflection caused by cutting force in different cutter directions and proposed a cutter deflection model. Mohsen $S^{[27]}$ proposed an application of virtual machining system to improve the accuracy and productivity of parts manufacturing by monitoring and minimizing tool deflection error. Zeroudi $\mathrm{N}$ ${ }^{[28]}$ proposed a cutter deflection calculation and compensation method based on the cutting force prediction model of free-form surface milling. Mamedov $\mathrm{A}^{[29]}$ investigated modeling of machining forces with shearing and plowing mechanisms and estimated instantaneous cutter deflections in micro end milling. Huo $\mathrm{D}^{[30]}$ investigated the cutter deflection during micro-milling and its effect on cutting force and surface generation. The distribution of cutting forces acting on the cutter was calculated with a mathematical model that considers cutter elasticity and runout, and the cutter deflection caused by the cutting forces was obtained. Zhang $X^{[31]}$ presented the modeling of cutting forces and instantaneous cutter deflection in the micro end milling process. Altintas $Y^{[32]}$ studied the deflections of both end mill and the blade under the cutting loads. The estimated deflections were compensated by modifying the tool path coordinates. Kim $\mathrm{G} \mathrm{M}^{[33]}$ presented a method to analyze the 3-dimensional form error of a ball-end milled surface due to the elastic compliance of the cutting tool. 
For the whole machining, deflection and cutting force have affected each other. The current research mainly focused on the prediction of cutter deflection, but the prediction of cutting force considering cutter deflection was not much.

This paper proposed a cutting force prediction model to solve the force-deflection coupling caused by the cutting force and deflection feedback. In this model, the geometry model of fillet-end cutter and the cutter deflection model are established. The undeformed chip thickness model according to cutter posture and cutter deflection is presented. Compared with previous models, the force-deflection coupling considering the feedback between force and cutter deflection is analyzed, and the iterative calculation of the cutting force considering the force-deflection coupling is carried out. The simulation results show that this model is more accurate than the previous cutting force prediction model. The structure of this paper is organized as: In section 2, the cutting force prediction model considering force-deflection coupling is introduced, which includes the cutter geometry model, the cutter deflection model, the undeformed chip thickness model, and the iterative method of forcedeflection. In section 3, the experimental setup is introduced, and the experimental results is discussed. The conclusions are drawn in section 4.

\section{Prediction of cutting force considering force-deflection coupling}

\subsection{Geometric modeling of fillet-end cutter}

As shown in Fig. 1(a), $R_{r}$ represents the radius of the center circle of the sweep surface of the filletend cutter edge, and $r$ represents the fillet radius of the arc edge. Each cutting edge is discrete into many cutting edge elements along the axis of the tool, and each cutting edge element could be represented by the axial position $z$ and the radial position angle $\Psi_{j}(z)$.

(a)

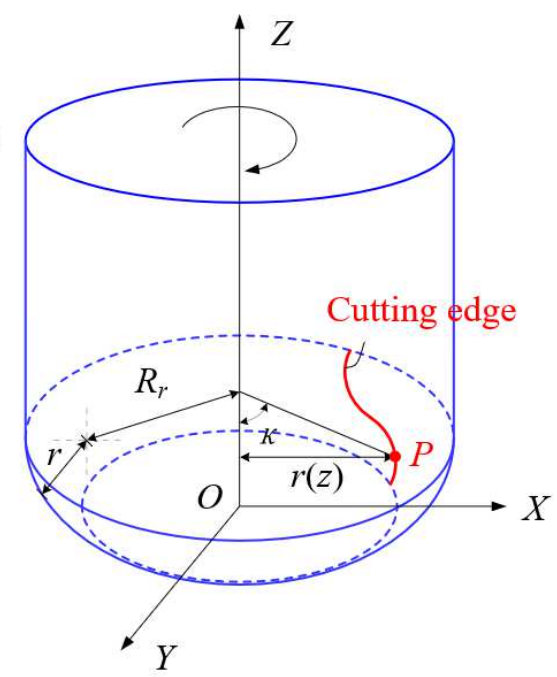

(b)

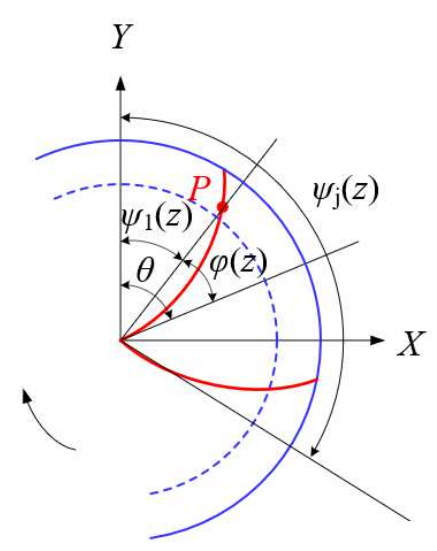

Fig. 1 Parameters of the fillet-end cutter

The cutting edge element $P$ in the figure could be expressed as:

$$
P=\left[r(z) \sin \psi_{j}(z) r(z) \cos \psi_{j}(z) \quad z\right]^{T}
$$

where $r(z)$ is the distance between the cutting edge element $P$ and the cutter axis. Then $r(z)$ could be expressed as:

$$
r(z)= \begin{cases}R_{r}+\sqrt{r^{2}-(r-z)^{2}} & , z<r \\ R_{r}+r & , z \geq r\end{cases}
$$


$\Psi_{j}(z)$ represents the radial position angle of the cutting edge element of the $j$ cutting edge at a height of $z$, and its geometric position is shown in Fig. 1 (b) which could be calculated by the following formula:

$$
\psi_{j}(\mathrm{z})=\theta+(\mathrm{j}-1) \frac{2 \pi}{N}-\varphi(\mathrm{z})
$$

where $\theta$ is the rotation angle of the spindle. The rotation angle of the spindle at time $t$ could be expressed as $\theta_{t}=\omega t . N$ is the number of cutting edges of the cutter, and $\varphi(z)$ represents the radial lag angle of the current cutting edge element relative to the first cutting edge element on the same cutting edge, which could be calculated by the following formula:

$$
\varphi(\mathrm{z})=\left\{\begin{array}{lr}
z \cdot \tan \left(\arctan \left(\tan \beta_{t} \cdot \sqrt{r^{2}-(\mathrm{r}-z)^{2}} / r\right)\right) / R_{r}+r & , z<r \\
z \cdot \tan \beta_{t} / R_{r}+r & , z \geq r
\end{array}\right.
$$

In the above formula, $\beta_{t}$ is the nominal helix angle of the cutter. When the cutter is right-handed, $\beta_{t}$ is negative.

The outward normal vector at the point $P$ on the cutting edge element could be expressed by the following formula:

$$
n(\mathrm{z})=\left[\begin{array}{lll}
\sin \kappa \sin \psi_{j}(\mathrm{z}) & \sin \kappa \cos \psi_{j}(\mathrm{z}) & -\cos \kappa
\end{array}\right]^{T}
$$

where $\kappa$ is the axial contact angle, then the axial contact angle of the cutting edge element on the fillet-end cutter could be calculated by the following formula:

$$
\kappa= \begin{cases}\arccos \frac{r-z}{r} & , z<r \\ \frac{\pi}{2} & , z \geq r\end{cases}
$$

\subsection{Modeling of deflection induced by cutting force}

Two adjacent cutter location points (CLP) $P_{L(n)}$ and the corresponding cutter axis vectors $V_{n}$ could be extracted from the cutter location file to determine the relative position and posture of the cutter in the workpiece coordinate system (WCS). As shown in Fig. 2, the two adjacent tool sites of $t$ at a certain time are $P_{L(n)}$ and $P_{L(n+1)}$ respectively, and the corresponding two cutter axis vectors are $V_{n(n)}$ and $V_{n(n+1)}$ respectively. According to linear vector interpolation and angle vector interpolation, the cutter location point $P_{L(t)}$ and cutter axis vector $V_{n(t)}$ in the workpiece coordinate system at time $t$ could be obtained. The lead angle $\alpha$ is the rotation angle between the cutter axis vector $V_{n(t)}$ and the normal vector $n$ of the surface. The tilt angle $\beta$ was the rotation angle from feed direction $a$ to the projection of $V_{n(t)}$ on the tangent plane at the cutter contact point ${ }^{[34]}$. In addition, the corresponding cutter location feed vector (represented by $v_{L}$ ) is expressed as:

$$
v_{L(t)}=P_{L(n+1)}-P_{L(n)}
$$

In five-axis milling, the $Z$-axis of the cutter coordinate system (CCS) is consistent with the direction of the cutter axis vector. The $Y$-axis of the CCS is perpendicular to the direction of the cutter axis vector and the direction of the feed vector. The $X$-axis of the CCS is determined by Cartesian right hand rule. The three vectors of the CCS could be expressed as: 


$$
\left\{\begin{array}{l}
x_{L}=\frac{\mathrm{y}_{L} \times z_{L}}{\left\|\mathrm{y}_{L} \times z_{L}\right\|} \\
\mathrm{y}_{L}=\frac{z_{L} \times v_{L}}{\left\|z_{L} \times v_{L}\right\|} \\
z_{L}=\frac{V_{n}}{\left\|V_{n}\right\|}
\end{array}\right.
$$

The rotation transformation matrix from the CCS to the WCS at time $t$ is expressed as:

$$
{ }_{L(\mathrm{t})}^{W} R=\left[\begin{array}{lll}
x_{L(\mathrm{t})} & y_{L(\mathrm{t})} & z_{L(\mathrm{t})}
\end{array}\right]
$$

However, when the cutter deflection is induced, the CCS still conforms to the Eq. (8). The rotation transformation matrix between the deflected CCS and the undeflected CCS be expressed as:

$$
R_{R}=\left[\begin{array}{ccc}
\cos \delta & 0 & \sin \delta \\
0 & 1 & 0 \\
-\sin \delta & 0 & \cos \delta
\end{array}\right]
$$

Since the cutter deflection is considered, the deflected and undeflected cutter center circle are not coincidence. It is assumed that two element sections remain to be in a plane before and after the cutter deflection. But the two sections rotate at a deflection angle $\delta$ around center axis respectively, which is defined as the angle between the tangent line of a point on the axis after deflection and the axis before deflection. As shown in Fig. 3, the angle between the projection of the deflected cutter tip on the CCS and the positive direction of $Y$-axis is called deviation angle which denoted as $\tau$. The displacement from the point on the axis after deflection to the axis before deflection is called $\rho . m$ represents the projected length of the deflected length in the undeflected $Z$-axis direction, and $L$ represents the length of the overhanging part. Due to the uneven distribution of the force loaded on the cutter during the cutting process, this paper regards the cutting force as concentrated on a certain point of the cutting edge of the cutter for the convenience of analysis ${ }^{[35]}$. The radial bending deflection and axial bending deflection caused by the element force $(\mathrm{d} f)$ as shown in Fig. 2. The calculation formula could be described as:

$$
\begin{aligned}
& \mathrm{d} f_{\text {radial }}=\sqrt{\left(\mathrm{d} f_{x}\right)^{2}+\left(\mathrm{d} f_{y}\right)^{2}} \\
& \mathrm{~d} f_{\text {axial }}=\mathrm{d} f_{z}
\end{aligned}
$$

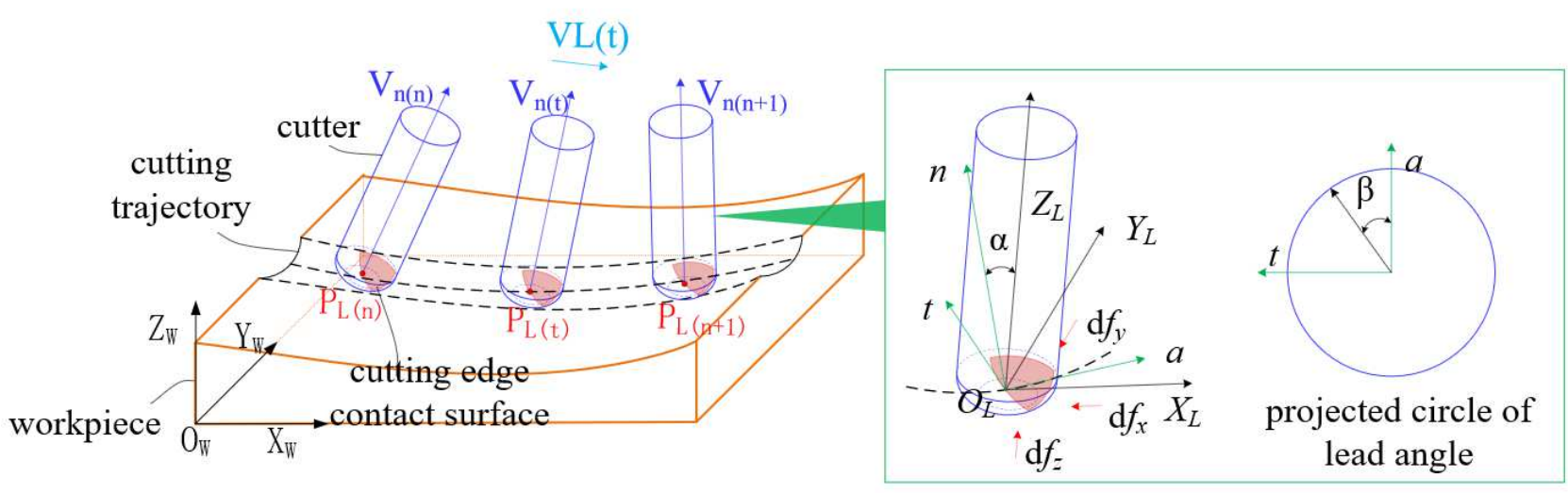

Fig. 2 Components of generated cutting force by cutter workpiece engagement 
In the process of five-axis milling, the small diameter cutter is deflected due to the chip reaction force, which is mainly manifested in the radial and axial bending deflection of the cutter. The radial bending deflection of the cutter would change the cutting trajectory of the cutting edge, thus the calculation of the instantaneous micro-deflection cutting thickness of the cutting edge element is affected. To describe the deflection of the cutter, two coordinate systems are set up. As shown in Fig. 3 , the origin of the WCS is fixed on the workpiece. The CCS moves along the feed direction of the cutter relative to the WCS, and moves in the direction of translation and rotation relative to the CCS.
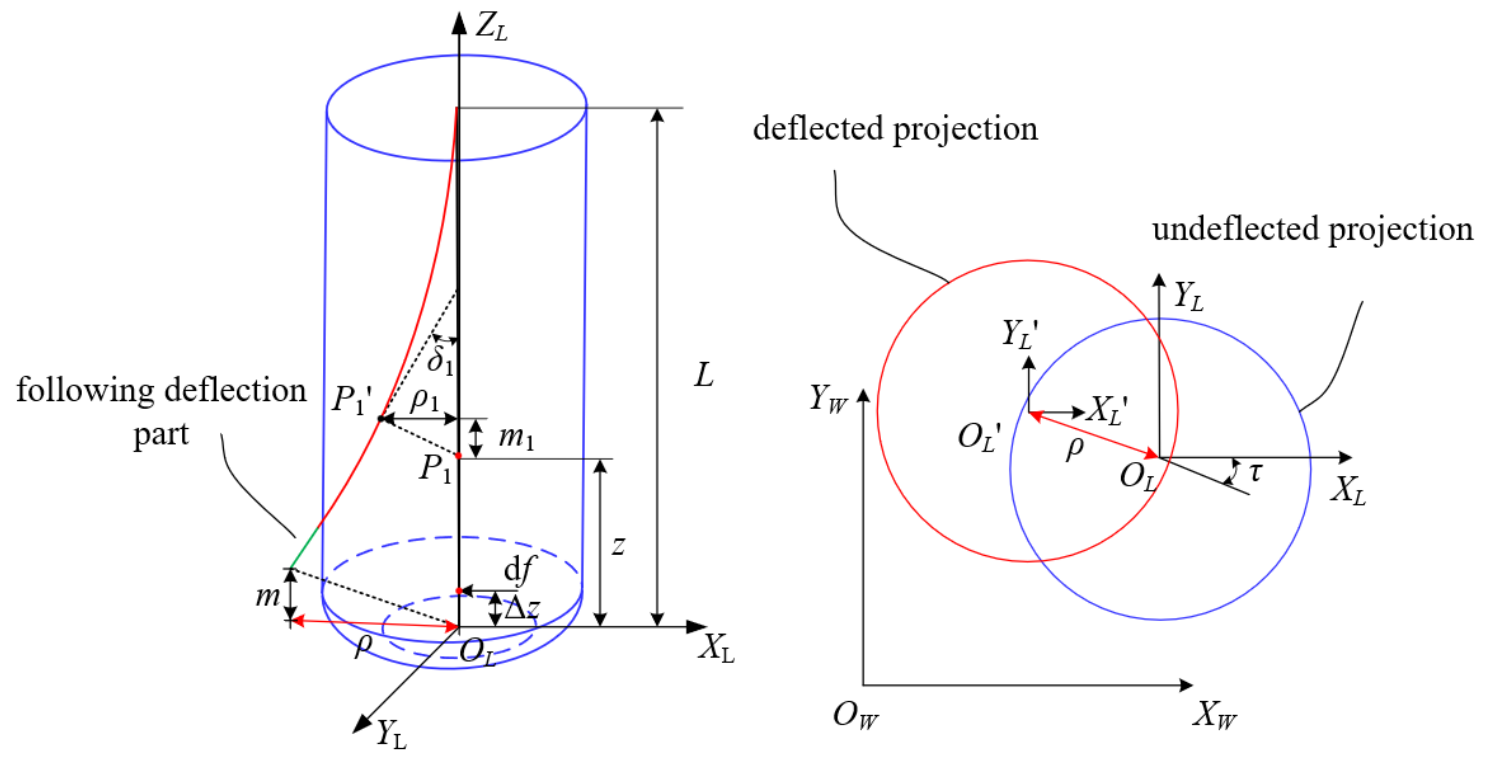

Fig. 3 Geometric relationship of deflected cutter location point

The projection of reduction of cutter length along $Z$ axis caused by the deflection could be calculated by

$$
m=\frac{\mathrm{d} f_{\text {axial }} \cdot r}{E A}+\frac{\mathrm{d} f_{\text {axial }} \cdot(\mathrm{L}-r)}{E A}
$$

Since the following deviation occurs below the action point of the element force, the deflection law of the upper and lower parts of the action point of the element force is different in the CCS. Therefore, the displacement in the cutter axial direction under the radial element force could be calculated by

$$
\left\{\begin{array}{c}
\rho(\mathrm{z})=\frac{\mathrm{d} f_{\text {radial }}}{E I}\left(-\frac{1}{6} \mathrm{z}^{3}+\frac{\Delta z}{2} \mathrm{z}^{2}+\frac{L^{2}}{2} z-L \Delta z z+\frac{L^{2}}{2} \Delta z-\frac{1}{3} \mathrm{~L}^{3}\right) \\
\delta(\mathrm{z})=\frac{\mathrm{d} f_{\text {radial }}}{E I}\left(\frac{1}{2} \mathrm{z}^{2}+\Delta z z+\frac{1}{2} \mathrm{~L}^{2}-\mathrm{L} \Delta z\right) \\
\rho(\mathrm{z})=\frac{\mathrm{d} f_{\text {radial }}}{E I}\left(\frac{1}{3} \Delta z^{3}-\mathrm{L} \Delta z^{2}+\mathrm{L}^{2} \Delta z-\frac{1}{3} \mathrm{~L}^{3}\right)+(\Delta z-z) \sin \delta(\mathrm{z}) \\
\delta(\mathrm{z})=\frac{\mathrm{d} f_{\text {radial }}}{E I}\left(\frac{3}{2} \Delta z^{2}+\frac{1}{2} \mathrm{~L}^{2}-\mathrm{L} \Delta z\right)
\end{array}\right\}, z>\Delta z
$$

\subsection{Modeling of undeformed chip thickness}

According to the definition of deflection and deflection angle of cutter, the translate transformed matrix between two coordinate systems before and after cutter deflection could be expressed as 


$$
T_{R}=\left[\begin{array}{c}
-\rho(\mathrm{z}) \sin \tau \\
-\rho(\mathrm{z}) \cos \tau \\
\mathrm{m}
\end{array}\right]
$$

In the cutting process showed in Fig. 4, to describe relative position and posture of the cutter in the WCS, $\left(P_{n}, V_{A(t)}\right)$ represents the CLP and cutter axis vector at time $t$. Then, according to the transformation in Eq. 14, the CLP $P_{n}{ }^{\prime}$ and cutter axis vector $V_{A(t)}{ }^{\prime}$ after deflection could be calculated as

$$
\begin{aligned}
P_{t}^{\prime} & =P_{t}+{ }_{L}^{W} \mathrm{R} \cdot T_{R} \\
V_{\mathrm{t}}^{\prime} & ={ }_{T}^{W} R\left[R_{R}\right]\left[{ }_{T}^{W} R\right]^{-1} V_{\mathrm{t}}
\end{aligned}
$$

Considering the cutter deflection, the rotation transformation matrix ${ }_{L}^{W} R$ ' from CSL to CSW at time $t$ is

$$
{ }_{L(\mathrm{t})}^{W} R^{\prime}=R_{R} \cdot \stackrel{W}{W(\mathrm{t})} R
$$

So the composition transformation matrix from CSL to CSW at time $t$ is

$$
\underset{\mathrm{L}(\mathrm{t})}{W} T_{C}=\left(\begin{array}{cc}
{ }_{(\mathrm{t})}^{W} R^{\prime} & p_{n(\mathrm{t})}^{\prime} \\
0 & 1
\end{array}\right)
$$

Similarly, the composition transformation matrix from CSL to CSW at time $t+\Delta t$ is

$$
{ }_{L(t+\Delta t)}^{W} T_{C}=\left(\begin{array}{cc}
{ }_{L(\mathrm{t})}^{W} R_{(t+\Delta t)}^{\prime} & p_{n(t+\Delta t)}^{\prime} \\
0 & 1
\end{array}\right)
$$

At time $t$, the descriptions of the cutting edge element $p_{n(\mathrm{t})}$ in CSL and CSW, ${ }^{L} p_{n(\mathrm{t})}$ and ${ }^{W} p_{n(\mathrm{t})}$, have the following mapping relationship:

$$
\left(\begin{array}{c}
{ }^{W} p_{n(\mathrm{t})}^{\prime} \\
1
\end{array}\right)={ }_{L(\mathrm{t})}^{W} T_{C}\left(\begin{array}{c}
{ }^{L} p_{n(\mathrm{t})}^{\prime} \\
1
\end{array}\right)
$$

Similarly, the description of the cutting edge element $p_{n(\mathrm{t}+\Delta \mathrm{t})}$ in CSL and CSW, ${ }^{L} p_{n(\mathrm{t}+\Delta \mathrm{t})}$ and ${ }^{W} p_{n(\mathrm{t}+\Delta \mathrm{t})}$, has the following mapping relationship.

$$
\left(\begin{array}{c}
{ }^{W} p_{n(\mathrm{t}+\Delta \mathrm{t})}^{\prime} \\
1
\end{array}\right)={ }_{L(\mathrm{t}+\Delta \mathrm{t})} T_{C}\left(\begin{array}{c}
{ }^{L} p^{\prime}{ }_{n(\mathrm{t}+\Delta \mathrm{t})} \\
1
\end{array}\right)
$$

In the WCS, based on the two position vectors of the cutting edge element in the adjacent cutting edge periods, the feed vector of the cutting edge element in the WCS at time $t$ could be expressed as

$$
{ }^{W} v_{L(t)}^{\prime}={ }^{W} \mathbf{p}_{n(\mathrm{t}+\Delta \mathrm{t})}^{\prime}-{ }^{W} \mathbf{p}_{n(\mathrm{t})}^{\prime}
$$

The expression of the cutting edge element feed vector in the WCS mapping to the spindle deflection coordinate system is

$$
{ }^{L} v_{L(t)}=\left[{ }_{L(\mathrm{t})}^{W} R^{\prime}\right]^{-1}{ }^{W} v^{\prime}{ }_{L(t)}
$$

After deflection, the outward normal vector of cutter sweep $n^{\prime}(z)$ is calculated as

$$
n^{\prime}(z)=\left[R_{R}\right] \cdot n(z)
$$


In this way, the feed vector of the cutting edge element could be obtained at time $t$. The undeformed chip thickness of the cutting edge element is defined as the projection length of the minimum feed vector of the cutting edge element in the previous tooth cycle, which is on the normal vector of the swept surface of the cutter. The calculation formula for the undeformed chip thickness of the cutting edge element is as follows.

$$
h_{\mathrm{t}}(\mathrm{z})={ }^{L} v_{L(t)} \cdot n^{\prime}(z)
$$
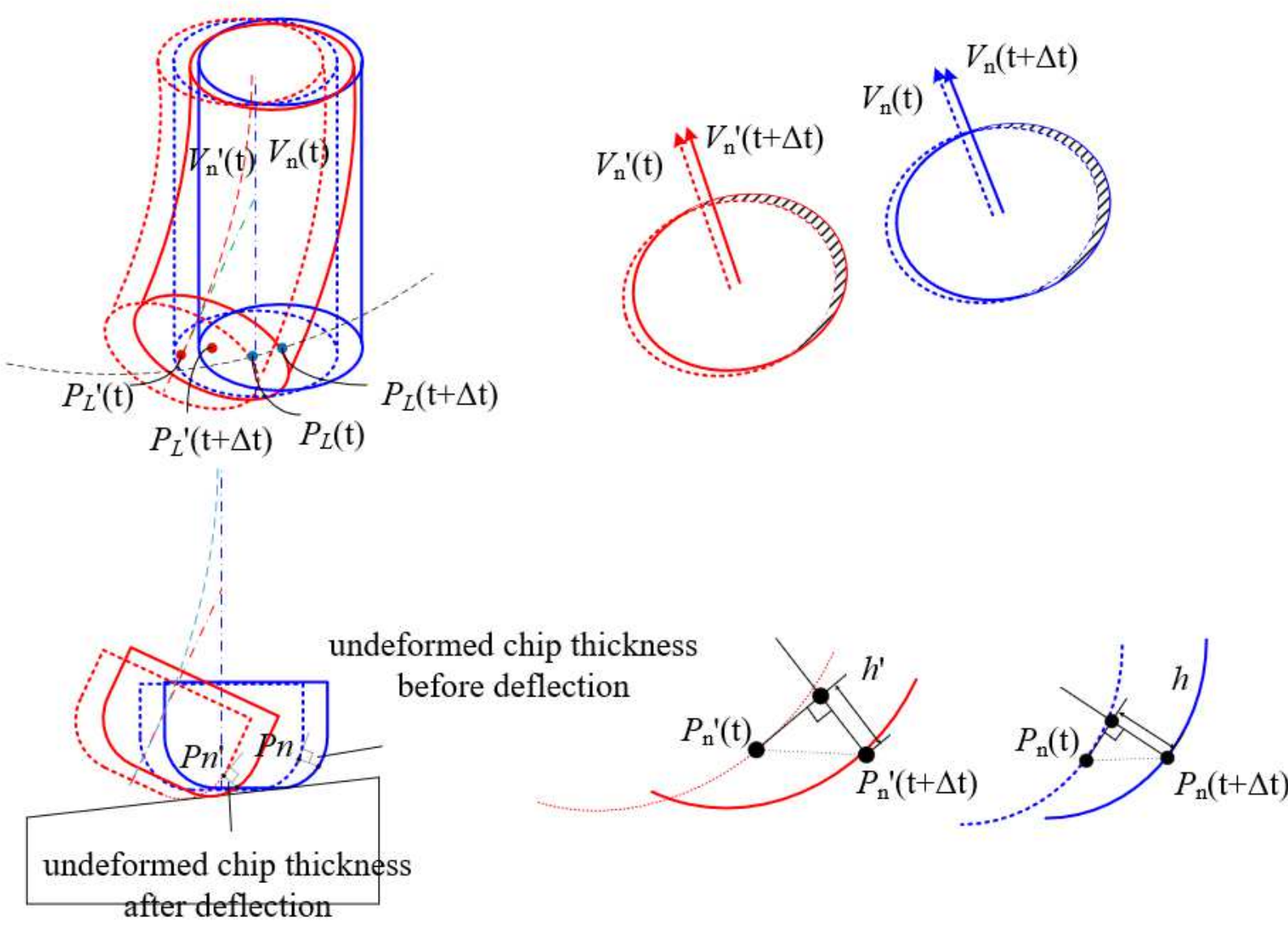

Fig. 4 Chip thickness before and after cutter deflection

To predict the cutting force model accurately, cutter workpiece engagement (CWE) needs to be obtained. The method to determine the CWE was presented by defining two basic conditions and five types of cutting edge elements which is detailed shown in Table $1^{[36]}$.

Table 1 Cutting edge element types and CWE analysis

\begin{tabular}{lllll}
\hline Type & $\begin{array}{l}\text { Whether it is outside } \\
\text { the workpiece } \\
\text { surface }\end{array}$ & $\begin{array}{l}\text { Whether it is inside the } \\
\text { envelope of previous } \\
\text { cutting edge }\end{array}$ & $\begin{array}{l}\text { Whether it is below the } \\
\text { envelope of previous } \\
\text { cutting edge }\end{array}$ & $\begin{array}{l}\text { Whether it } \\
\text { involved in cutting } \\
\text { process }\end{array}$ \\
\hline 1 & $\mathrm{Y}$ & - & - & $\mathrm{N}$ \\
2 & $\mathrm{Y}$ & - & - & $\mathrm{N}$ \\
3 & $\mathrm{~N}$ & $\mathrm{Y}$ & - & $\mathrm{N}$ \\
4 & $\mathrm{~N}$ & - & $\mathrm{Y}$ & $\mathrm{Y}$ \\
5 & $\mathrm{~N}$ & $\mathrm{~N}$ & $\mathrm{~N}$ & $\mathrm{Y}$ \\
\hline
\end{tabular}

\subsection{Cutting force without consideration of deflection}


As shown in Fig. 5, the cutting edge is discretized into cutting edge elements along the cutter axis. And the cutting force of the element is defined as the product of the chip load area of the element and the unit cutting force coefficient.
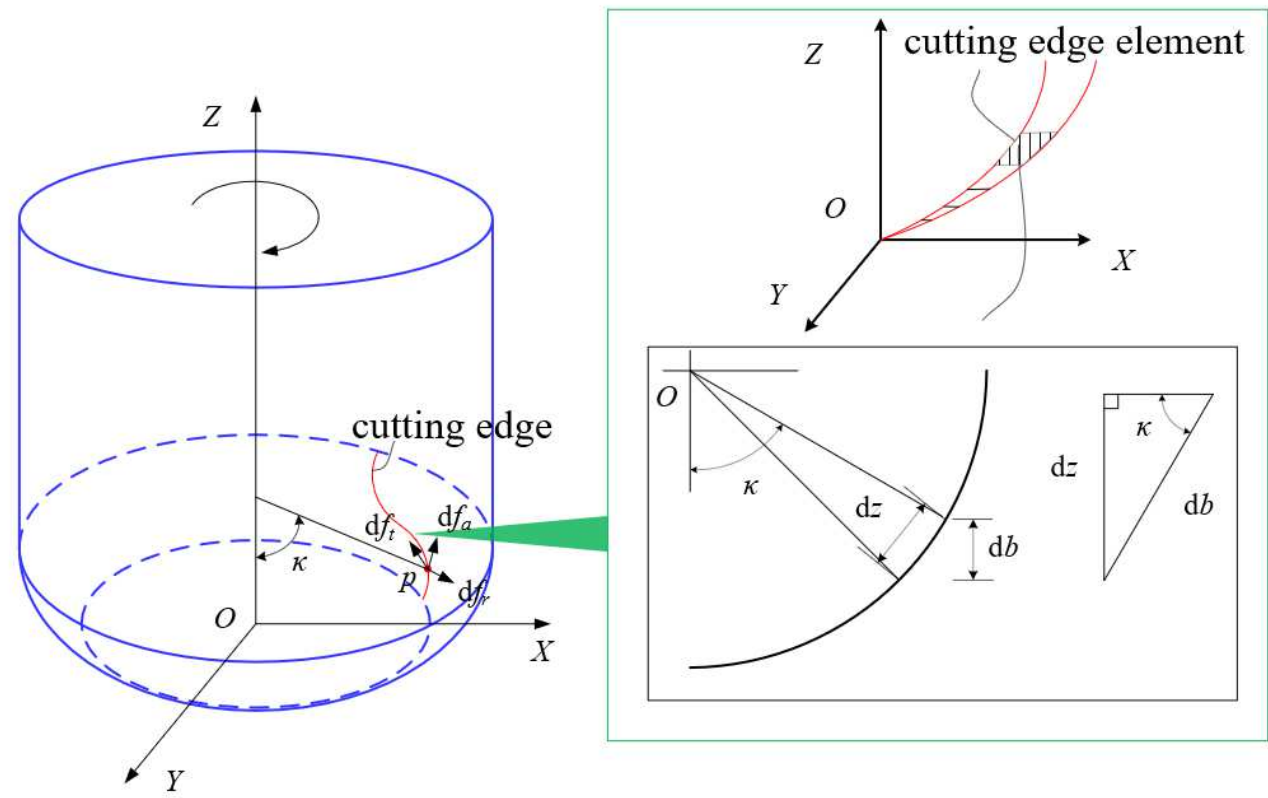

Fig. 5 Schematic diagram of undeformed chip width

The mechanical model of cutting force ${ }^{[1]}$ in radial, tangential and axial directions of the cutting edge element at time $t$ is

$$
\left\{\begin{array}{l}
\mathrm{d} f_{r}=k_{r} h\left(\psi_{j}(\mathrm{z}), z\right) \mathrm{d} b(z) \\
\mathrm{d} f_{t}=k_{t} h\left(\psi_{j}(\mathrm{z}), z\right) \mathrm{d} b(z) \\
\mathrm{d} f_{a}=k_{a} h\left(\psi_{j}(\mathrm{z}), z\right) \mathrm{d} b(z)
\end{array}\right.
$$

where, $k_{r}, k_{t}$ and $k_{a}$ represent the radial, tangential and axial cutting force coefficients of the cutting edge element respectively. Based on the measured data from the machining experiment, the cutting force coefficients calibration are carried out with the same workpiece material and cutter using general method which is given in another paper ${ }^{[36]}$.

$$
\left\{\begin{array}{l}
k_{t}\left(h_{j}\right)=3683.7+6637.16 e^{-49.3 h_{j}} \\
k_{r}\left(h_{j}\right)=1942.2+3901.8 e^{-44.6 h_{j}} \\
k_{a}\left(h_{j}\right)=-214.9-3444.8 e^{-123.1 h_{j}}
\end{array}\right.
$$

And $\mathrm{d} b(z)$ represents the undeformed chip width at the axial position $z$, which could be calculated by

$$
\mathrm{d} b(z)=\mathrm{d} z / \sin \kappa
$$

By integrating the discrete cutting edge elements along the cutter axis and adding up the cutting forces of all discrete cutting edges, the total cutting force model of all elements integral on all cutting edges on three axes is obtained as 


$$
\left\{\begin{array}{l}
f_{r}=\sum_{j=1}^{N}\left(\int_{0}^{z} k_{r} h\left(\psi_{j}(\mathrm{z}), z\right) \mathrm{d} b(z)\right) \\
f_{t}=\sum_{j=1}^{N}\left(\int_{0}^{z} k_{t} h\left(\psi_{j}(\mathrm{z}), z\right) \mathrm{d} b(z)\right) \\
f_{a}=\sum_{j=1}^{N}\left(\int_{0}^{z} k_{a} h\left(\psi_{j}(\mathrm{z}), z\right) \mathrm{d} b(z)\right)
\end{array}\right.
$$

The rotation transformation matrix between the element coordinate system and the CCS could be described as

$$
R=\left[\begin{array}{ccc}
-\sin \kappa \sin \psi & -\cos \psi & -\cos \kappa \sin \psi \\
-\sin \kappa \cos \psi & \sin \psi & -\cos \kappa \cos \psi \\
\cos \kappa & o & -\sin \kappa
\end{array}\right]
$$

The cutting force in the CCS could be expressed as

$$
\left[\begin{array}{l}
f_{x} \\
f_{y} \\
f_{z}
\end{array}\right]=R\left[\begin{array}{l}
f_{r} \\
f_{t} \\
f_{a}
\end{array}\right]
$$

According to the cutter geometry parameters (cutting edge number $N$, circular arc edge scanning the center circle radius $R_{r}$, circular arc edge radius $r$, cutter length of overhanging section $L$, nominal spiral angle $\beta_{t}$ ) and the material parameters (materials for 1045 steel, elastic modulus $E$ and moment of inertia $I$ ). Considering that the cutter deflection would affect the cutting depth, a deflection coefficient $\xi$ is introduced to approximately replace the change of cutter deflection on the cutting depth numerically. The corresponding relation formula of the cutting depth is

$$
\left\{\begin{array}{l}
\mathrm{d} a=\mathrm{d} a_{0}+r-r \cdot \cos \beta-R_{r} \cdot \sin \alpha+\xi \\
\xi \approx R_{r} \cos \delta+r(1-\sin \delta)-\mathrm{m}
\end{array}\right.
$$

Initial parameters $\left(t_{0}, z_{0}, N_{0}, \theta_{0}\right)$ are required. The cutting force without considering cutter deflection is calculated $\left(\mathrm{d} f_{x}, \mathrm{~d} f_{y}, \mathrm{~d} f_{z}\right)$.

\subsection{Cutting force considering force-deflection coupling}

As shown in Fig. 6, the calculation method of five-axis cutting force prediction is presented, which considers the influence of cutter posture and cutter deflection on the instantaneous undeformed chip thickness and cutting state of cutting edge to accurately predict cutting force.

Substituting Eq. (27) into deflection model, $\rho_{x}(z), \rho_{y}(z), \rho_{z}(z)$ could be calculated as

$$
\left\{\begin{array}{l}
\rho_{x, y}(\mathrm{z})=\frac{\mathrm{d} f_{\text {radial }}}{E I}\left(-\frac{1}{6} \mathrm{z}^{3}+\frac{\Delta z}{2} \mathrm{z}^{2}+\frac{L^{2}}{2} z-L \Delta z z+\frac{L^{2}}{2} \Delta z-\frac{1}{3} \mathrm{~L}^{3}\right), z>\Delta z \\
\rho_{x, y}(\mathrm{z})=\frac{\mathrm{d} f_{\text {radial }}}{E I}\left(\frac{1}{3} \Delta z^{3}-\mathrm{L} \Delta z^{2}+\mathrm{L}^{2} \Delta z-\frac{1}{3} \mathrm{~L}^{3}\right)+(\Delta z-z) \sin \delta, z<\Delta z \\
\rho_{z}(\mathrm{z})=\frac{\mathrm{d} f_{\text {axial }} \cdot r}{E A}+\frac{\mathrm{d} f_{\text {axial }} \cdot(\mathrm{L}-r)}{E A}
\end{array}\right.
$$

Through analysis, the cutter in the cutting process would be subjected to the workpiece on its reaction force, so the deflection in the $X-, Y$ - and $Z$-axis is induced under the cutting force. The cutter deflection under action of cutting force is $\rho(z)$. The undeformed chip thickness is decreased as 


$$
h^{\prime}\left(\psi_{j}(z), z\right)=h\left(\psi_{j}(z), z\right)-\rho(z)
$$

However, the cutter deflection makes the cutting edge of the cutter tend to be far away from the workpiece. It reduces the force of the workpiece on the cutter and the reaction force of the cutter on the workpiece. It could be seen from Eq. (31) that the deflection is proportional to the force. On the $X_{W} O_{W} Y_{W}$ plane when the force applying on the cutter decreases. The deflection $\rho$ of the cutter would also decrease. Similarly, when the $\rho$ becomes smaller, the force applying on the cutter would also decrease. The iterative calculation formula is as

$$
\left\{\begin{array}{l}
\mathrm{d} f_{q(i+1)}=k_{q} h_{i}\left(\psi_{j}(z), z\right) \mathrm{d} b(z) \\
h_{i}\left(\psi_{j}(z), z\right)=h_{i-1}\left(\psi_{j}(z), z\right)-\rho_{i}(z)
\end{array}\right.
$$

where $q=r, t, a, i=1,2,3 \ldots$ and $k_{q}$ is the radial, tangential and axial cutting force coefficients.

Finally, the new deflection would tend to be 0 , so that the difference value of force before and after calculation is close to 0 . For the convenience of calculation, the difference is expressed by em, so there is the following relationship

$$
e m=\left|\frac{\mathrm{d} f_{q(i+1)}-\mathrm{d} f_{q(i)}}{\mathrm{d} f_{q(i+1)}}\right|
$$

In practical calculation, em is taken as 1e-8, which is used to ensure both accuracy and efficiency. 


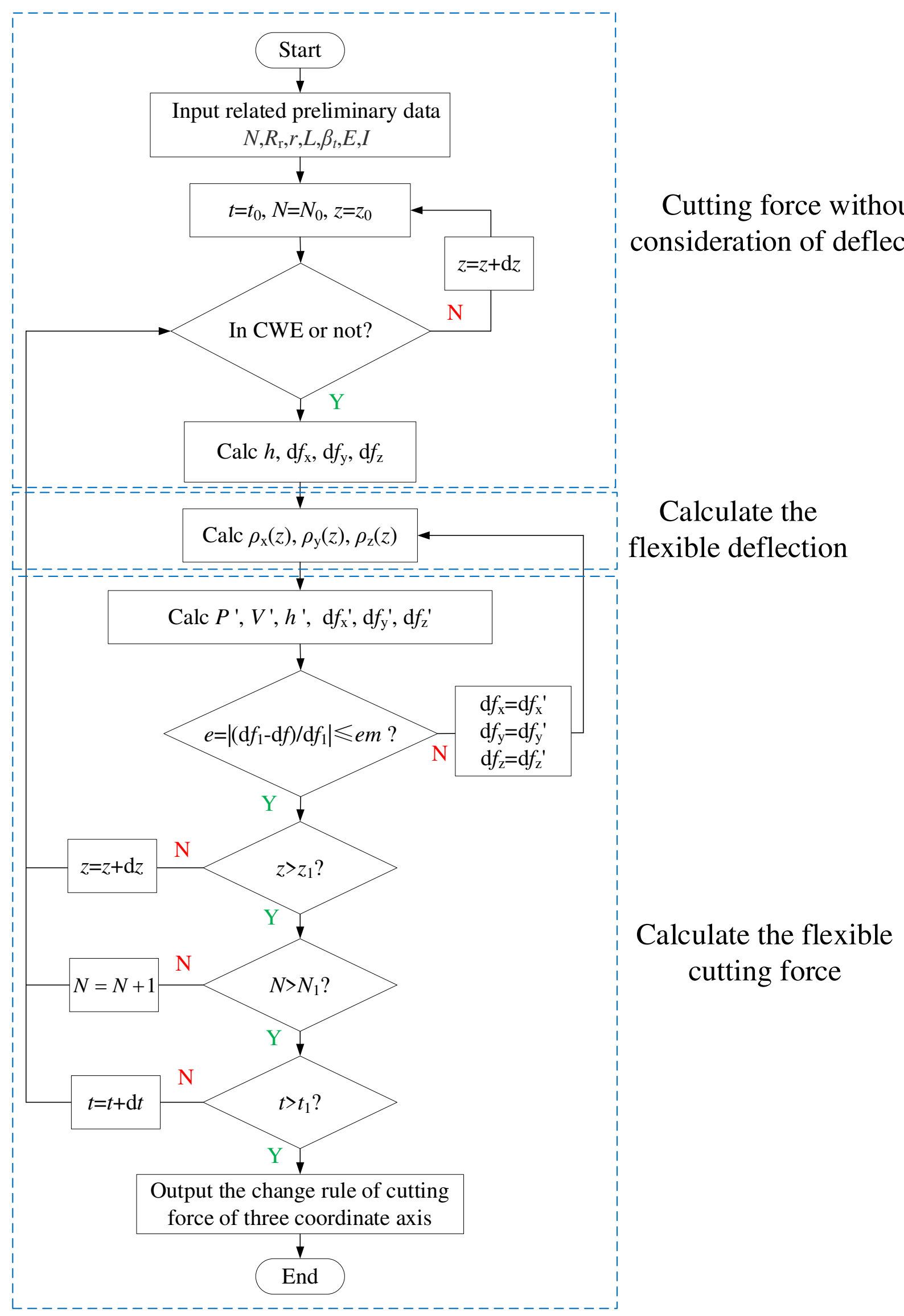

Fig. 6 Flow chart of cutting force prediction calculation considering force-deflection coupling 


\subsection{Experimental setup}

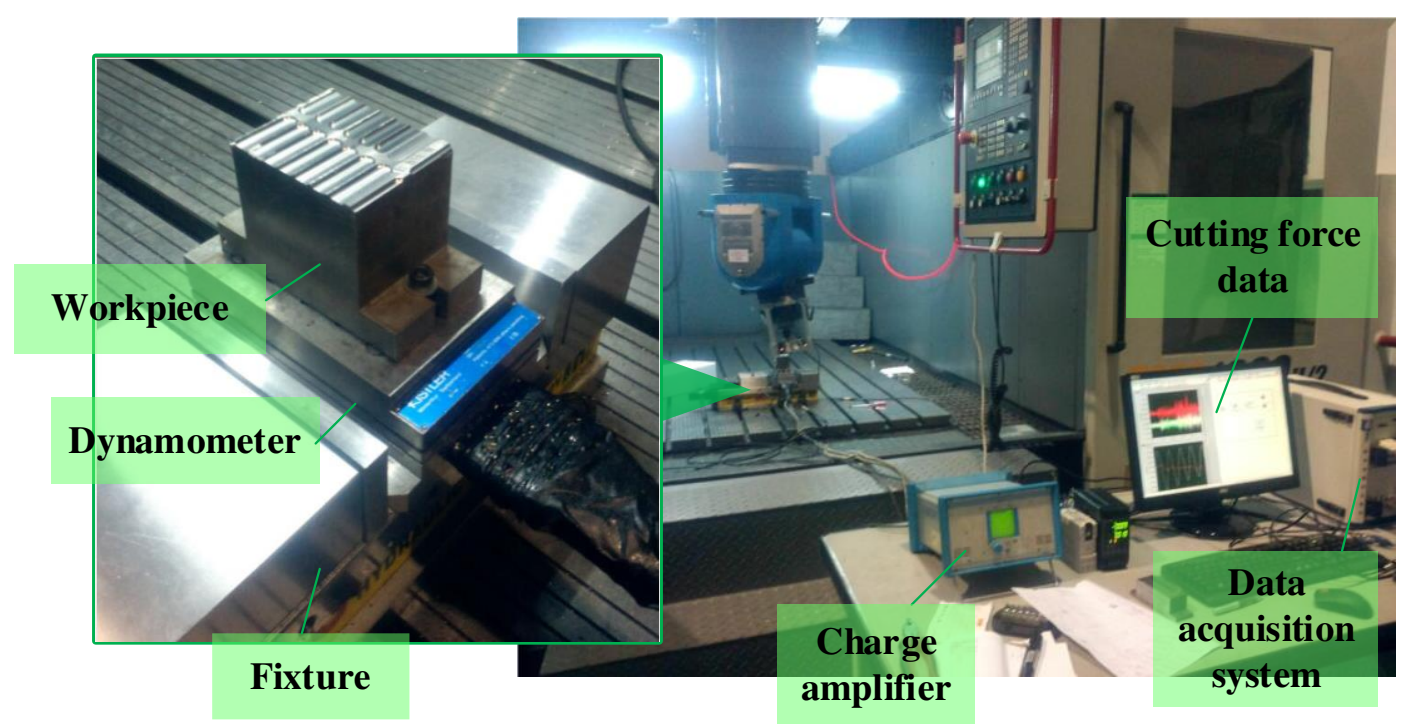

Fig. 7 Experiment platform

To verify the effectiveness of the cutting force model with force-deflection coupling feedback, the experiments in this paper are carried out on the five-axis milling center $\mathrm{GMC} 1600 \mathrm{H}$.

The mainly force measuring apparatus used in the machining process are Kistler9257A dynamic piezoelectric dynamometer and Kistler5070 charge amplifier. The workpiece material to be cut is 1045 steel (40CrNi2Si2MoVA, a low alloy carbon martensitic reinforced ultra-high strength steel) after heat treatment.

The used cutter is a cemented carbide integral end mill with a $10 \mathrm{~mm}$ diameter, and the model of the milling cutter is SANDVIK Coromant R216.24-10050EAK22H 1620. the geometric parameters of the milling cutter are shown in Table 2.

Table 2 Cutter parameters

\begin{tabular}{llll}
\hline Parameters & Value & Parameters & Value \\
\hline Cutter diameter $(\mathrm{mm})$ & 10 & Cutter fillet radius $(\mathrm{mm})$ & 2 \\
Number of cutter teeth & 4 & Cutter helix angle $(\mathrm{deg})$ & -50 \\
Total cutter length $(\mathrm{mm})$ & 100 & Cutter clamping length $(\mathrm{mm})$ & 20 \\
Length of the tooth $(\mathrm{mm})$ & 30 & Effective coefficient & 0.8 \\
\hline
\end{tabular}

The parameters set in the five-axis milling experiment are shown in Table 3, and the milling mode is slot milling. Parameters are selected through experiments of cutter, workpiece material, workpiece geometry, and engineering practice and many milling experiments are accomplished to keep the cutter in a good mechanical condition and make cutting forces change smoothly.

Table 3 Process parameters

\begin{tabular}{llll}
\hline Parameters & Value & Parameters & Value \\
\hline Cutting depth $(\mathrm{mm})$ & 1.5 & Feed per tooth $(\mathrm{mm} /$ tooth $)$ & 0.1 \\
Feed rate $(\mathrm{mm} / \mathrm{min})$ & 400 & Lead angle $(\mathrm{deg})$ & $0,5,10$ \\
Spindle speed $(\mathrm{r} / \mathrm{min})$ & 1000 & Tilt angle $(\mathrm{deg})$ & $-20,0,20$ \\
\hline
\end{tabular}

\subsection{Results and discussions}

According to the proposed cutting force model with considering force-deflection coupling in this paper, the predicted value of the cutting force model is compared with the measured value by 
simulation and experiment. The simulation calculation is carried out for the two cases with and without considering the force-deflection coupling, and then the simulation diagrams of the calculated values and the experimental measured values of the two cases are drawn respectively. Experiments were carried out on different cutter postures, as shown in Fig. 8. The lead angles of the cutter are $0^{\circ}$, $5^{\circ}, 10^{\circ}$ and the tilt angle is $0^{\circ}$ respectively. The left side of the figure shows the change rule of the predicted value and the experimental value of the cutting force model without considering the forcedeflection coupling. The right side of the figure shows the change rule of the predicted value and the experimental value of the cutting force model with considering the force-deflection coupling.

Overall, Fig. 8 shows the measured and predicted cutting forces along three orthogonal directions within a cutter rotation cycle. The bottom point is the measured cutting force of $X$-axis, and the bottom curve is the predicted cutting force distribution of $X$-axis. The top point is the measured cutting force of $Y$-axis, and the top curve is the predicted cutting force distribution of $Y$-axis. The middle point is the measured cutting force of $Z$-axis, and the middle curve is the predicted cutting force distribution of $Z$-axis. It could be clearly seen that the predicted value calculated by the cutting force model with considering force-deflection coupling is closer to the measured value than that calculated by the cutting force model without considering force-deflection coupling.

The predicted value of unconsidered force-deflection coupling is generally greater than the experimental value on $Y$-axis and $Z$-axis, and the absolute value of predicted value of unconsidered force-deflection coupling on $X$-axis is greater than the experimental value. This is because the cutting force is rigid cutting force when the force-deflection coupling is not considered, which is greater than the actual cutting force. The cutting force considering force-deflection coupling is slightly reduced after iteration calculation of cutting force, which is more in line with the experimental measured value. The $Y$-axis direction is the feed direction, so the force in $Y$-axis direction is greater than that in $X$-axis, $Z$-axis direction.
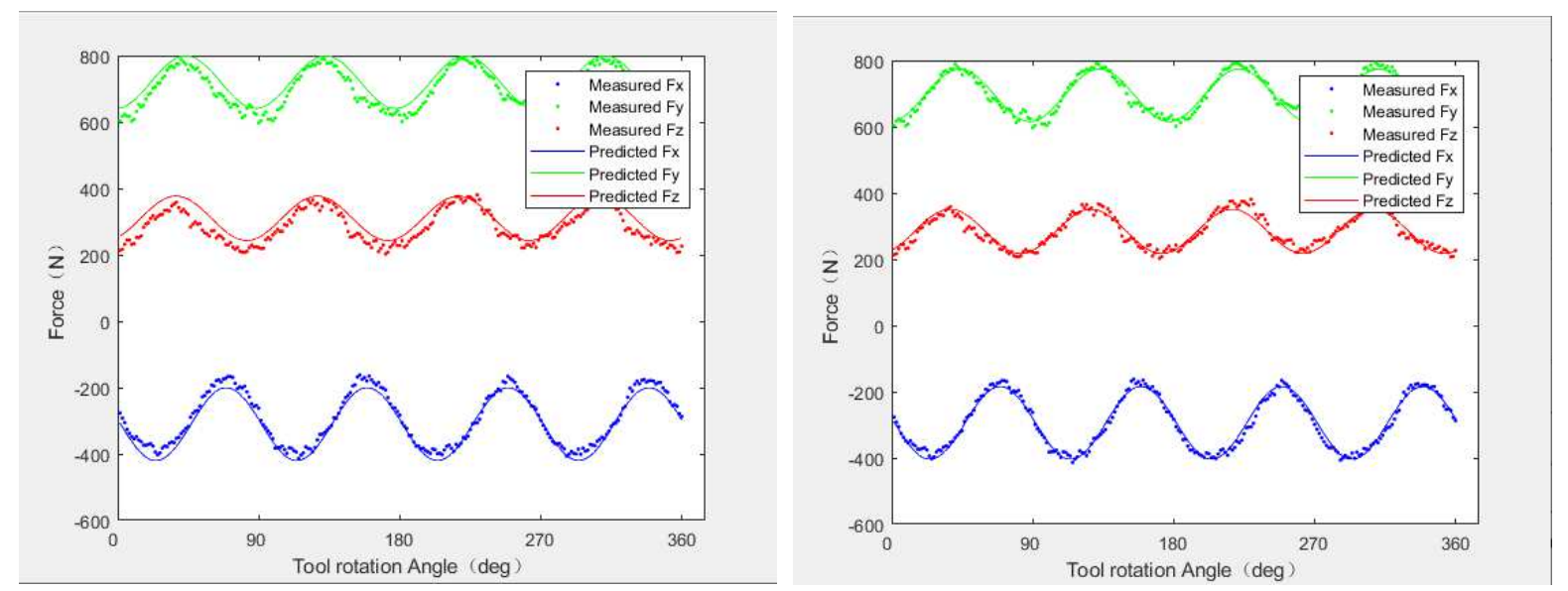

(a) The comparison between simulation and experiment of considering force-deflection coupling and without considering force-deflection coupling when the lead angle is $0^{\circ}$ and the tilt angle is $0^{\circ}$ 

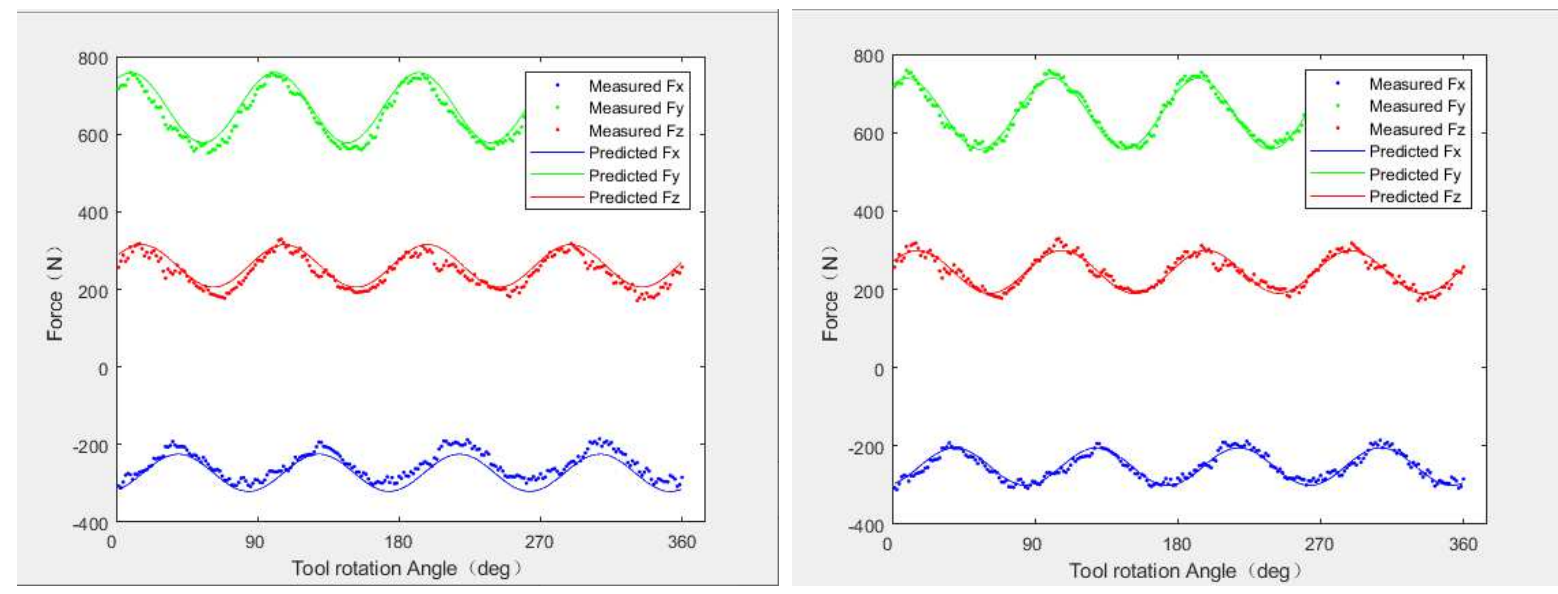

(b) when the lead angle is $5^{\circ}$ and the tilt angle is $0^{\circ}$
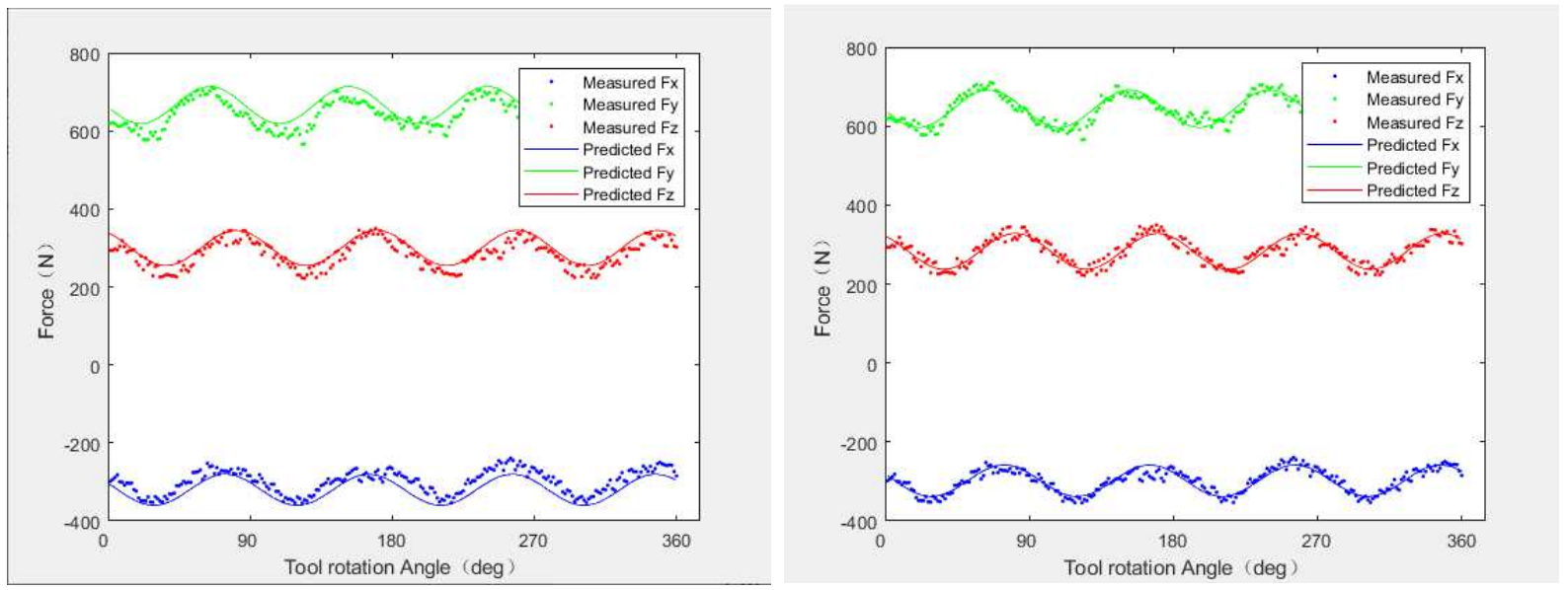

(c) when the lead angle is $10^{\circ}$ and the tilt angle is $0^{\circ}$

Fig. 8 When the tilt angle is $0^{\circ}$, the predicted values of cutting force are compared with the experimental values with different lead angles.

To verify the universality of the model, the lead angle is kept at $0^{\circ}$, and the tilt angles are simulated at $-20^{\circ}, 0^{\circ}$ and $20^{\circ}$ respectively, as shown in Fig. 9 . The comparison results show that the cutting force without considering force-deflection coupling is greater than that the model with considering force-deflection coupling, which further proves the accuracy of the model. In Fig. 9 , the error between the simulation value and the experimental value without considering force-deflection coupling is obvious at the peak, since the cutting edge contacts the workpiece and the undeformed chip thickness reaches the largest. At the peak, the cutter deflection is most obvious, when the forcedeflection coupling is considered, the effect of cutting force reduction caused by iteration is more significant, so the error between the simulation value and the experimental value without considering the cutter deflection at the peak is the largest. When the tilt angles are $-20^{\circ}$ and $20^{\circ}$, the angles are equal with different directions, so there is little difference for the force value in $Y$-axis which is the feed direction. 

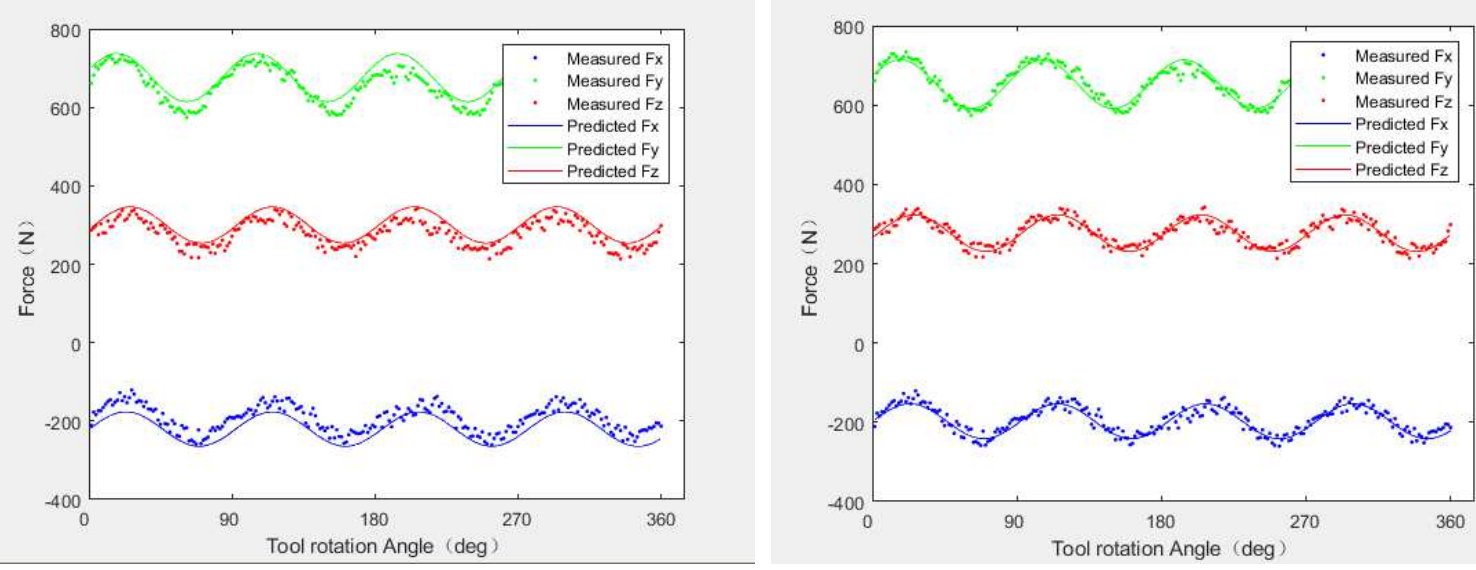

(a) The comparison between simulation and experimental of considering force-deflection coupling and without considering force-deflection coupling when the lead angle is $10^{\circ}$ and the tilt angle is $-20^{\circ}$
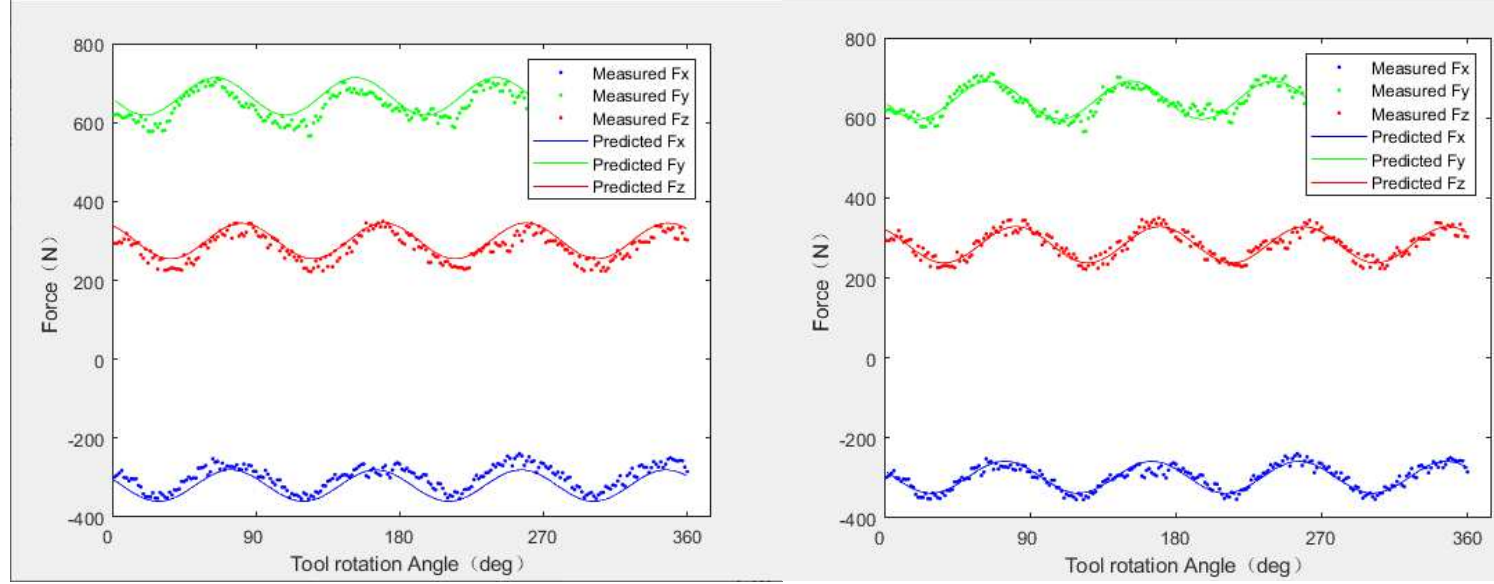

(b) when the lead angle is $10^{\circ}$ and the tilt angle is $0^{\circ}$
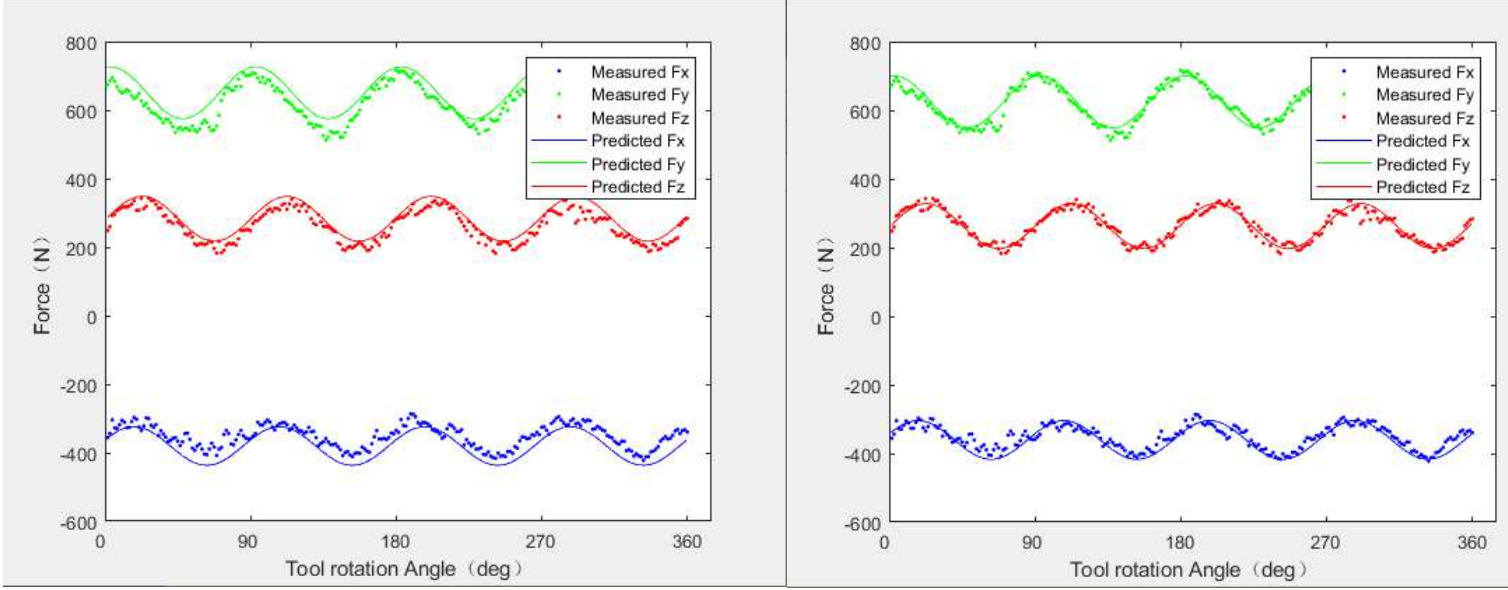

(c) when the lead angle is $10^{\circ}$ and the tilt angle is $20^{\circ}$

Fig. 9 When the lead angle is $10^{\circ}$, the predicted values of cutting force are compared with the experimental values with different tilt angles.

Fig. 10 shows the maximum error between the model without considering force-deflection coupling and the experimental value, and the maximum error between the model with considering force-deflection coupling and the experimental value. It could be seen from the figure that the maximum errors of the prediction model without considering the force-deflection coupling in the $X$ axis, $Y$-axis and $Z$-axis are $15 \%, 27 \%$ and $15 \%$ respectively. Since the $Y$-axis direction is close to the feed direction, the cutter deflection of the $Y$-axis is the main deflection, so the error between the 
predicted value and the experimental value in the $X$-axis is greater. The maximum error of the prediction model considering force-deflection coupling proposed in this paper is less than $10 \%$ in the $X$-axis, less than $6 \%$ in the $Y$-axis, and less than $8 \%$ in the $Z$-axis. It is concluded that the prediction model considering force-deflection coupling proposed in this paper could be accurate for different cutter postures.
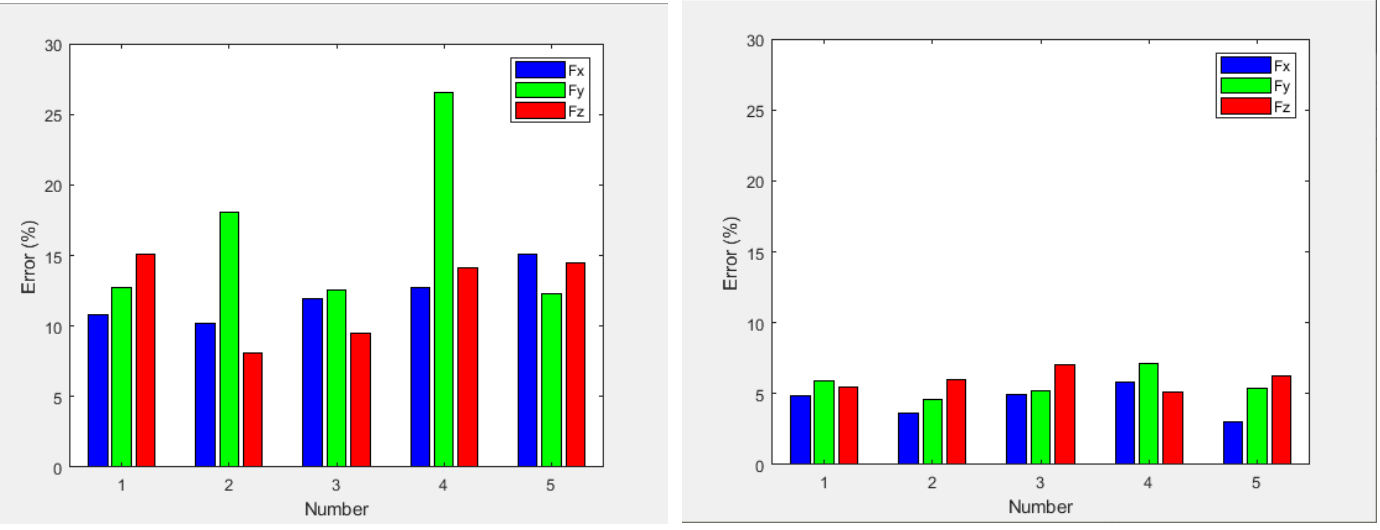

Fig. 10 The maximum error without considering the force-deflection coupling model and the maximum error with considering the force-deflection coupling model

The above simulation results show that the cutting force prediction model proposed in this paper has enough stability, so the cutting force prediction of different cutter postures is carried out through the prediction model, and its law is analyzed. Fig. 11(a) shows the effect of different lead angles on cutting force when the tilt angle is $0^{\circ}$. Under fixed depth cutting, the lead angle increases from $0^{\circ}$ to $20^{\circ}$ and the contact area decreases gradually, resulting in the decrease of average cutting force. Fig. 11(b) shows the effect of different tilt angles on cutting force when the lead angle is $10^{\circ}$. When the tilt angle increases from $0^{\circ}$ to $20^{\circ}$, the contact area decreases gradually, and the average cutting force has a decreasing trend. Further about the change rate of cutting force, it is found that the decrease rate of average cutting force caused by the increase of lead angle is slower than that caused by the increase of tilt angle. Because the variations of cutter posture angles would directly impact on the cutterworkpiece engagement which would determine the quantity of involved cutting edge elements. It reflects that the influence of the tilt angle on the contact area is greater than the lead angle in this experimental setup. It could be seen that optimized cutter posture could effectively reduce the cutting force and thus improve the processing quality and increase the cutter life.
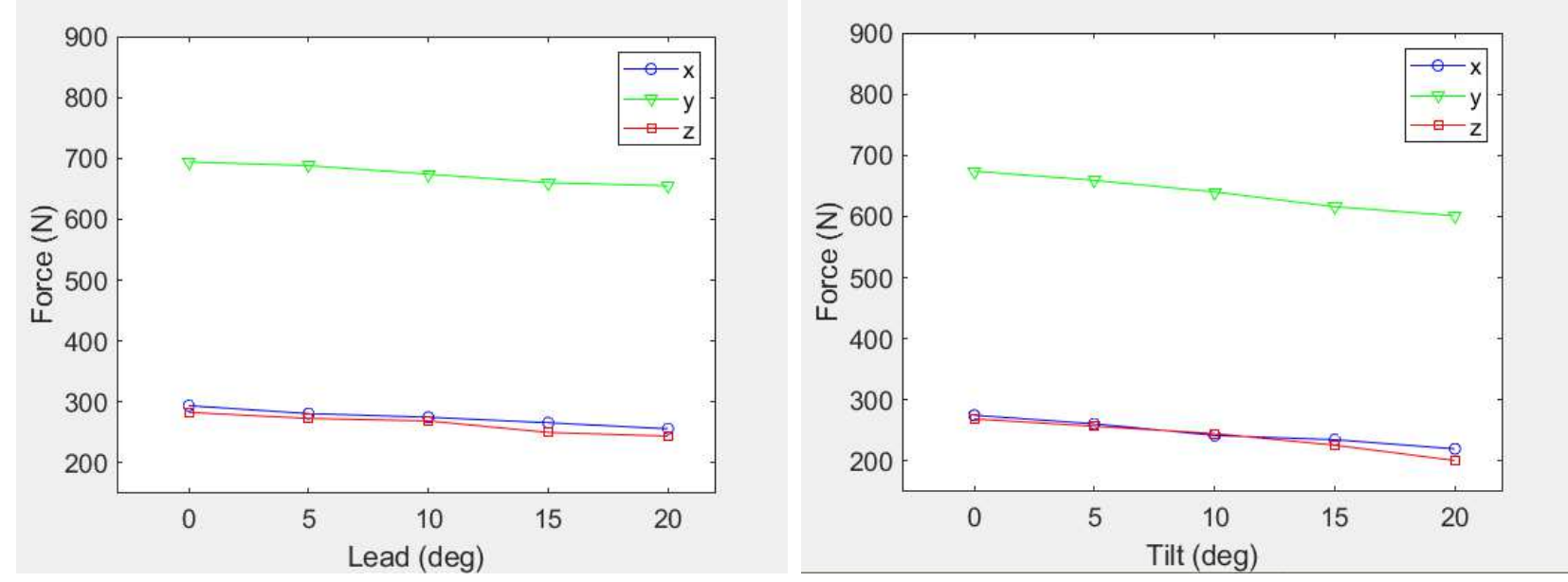

(a) Influence of lead angle on cutting force when the tilt angle is $0^{\circ}$ (b) Influence of tilt angle on cutting force when the lead angle is $10^{\circ}$ 
Fig. 11 Influence of cutter posture on cutting force.

\section{Conclusions}

This paper proposed the undeformed chip thickness model considering the cutter posture and cutter deflection by analyzing the interaction between force and deflection based on the established geometric model of the fillet-end cutter according to the geometric characteristics. The calculation method of cutting force prediction based on analysis of relationship between force and deflection for five-axis machining is presented, which contains the influence of cutter posture and cutter deflection for more accurately prediction of the cutting force. The experiments were designed and conducted to verify the effectiveness of the presented cutting force model taking the force-deflection coupling into account by contrast with model neglecting the cutter deflection. Influence of cutter posture on cutting force were studied using the verified cutting force model for better cutter orientation planning in fiveaxis milling under condition of machining difficult-to-cut material. Based on this research, the following conclusions could be drawn.

(1) There are $17 \%, 9 \%$, and $7 \%$ reduced rate of prediction error of cutting force along $X$-axis, $Y$ axis and $Z$-axis respectively using the model considering force-deflection coupling than that neglecting force-deflection coupling, which shows the effectiveness of the proposed prediction method.

(2) Using the same process parameters set in the experiment, the cutting force simulation is carried out applying the validated prediction model, which reflects a series of changing rules between cutting forces and cutter orientations. When the lead angle or tilt angle increases from $0^{\circ}$ to $20^{\circ}$, the average cutting force would decrease gradually, which illustrates the effect of cutter orientation on the cutting force. Further, the influence of tilt angle on cutting force is greater than that of lead angle under the experimental conditions, whose reason is that the tilt angle has greater impact on the cutter-workpiece engagement which directly impacts on the cutting force.

(3) The relationship between the cutting force and the cutter posture angles could be used in cutter orientation planning for optimizing the machining process. Based on the proposed prediction method, the cutting mechanism and process are further revealed, which could contribute to the industrial applications such as improving the cutter condition monitoring and the cutter orientation planning, especially for conditions of machining difficult-to-cut material.

\section{Acknowledgements}

This work was supported by National Natural Science Foundation of China under Grant No. 52005201.

\section{Abbreviations and Nomenclature}

\begin{tabular}{|l|l|}
\hline$P$ & Element of cutting edge \\
\hline$r$ & Fillet radius of the arc edge \\
\hline
\end{tabular}




\begin{tabular}{|l|l|}
\hline$R_{r}$ & $\begin{array}{l}\text { Radius of the center circle of the sweep surface of the fillet-end } \\
\text { cutter edge }\end{array}$ \\
\hline$z$ & Axial position \\
\hline$\kappa$ & Axial contact angle \\
\hline$\psi_{j}(z)$ & Radial position angle \\
\hline$j$ & Cutting edge number \\
\hline$N$ & Number of cutting edges of the cutter \\
\hline$\theta$ & Rotation angle of the spindle \\
\hline$\varphi(z)$ & Radial lag angle \\
\hline$\beta_{t}$ & Nominal helix angle \\
\hline$\delta$ & Deflection angle \\
\hline$\tau$ & Deviation angle \\
\hline$\rho$ & Deflection of cutter \\
\hline$m$ & $\begin{array}{l}\text { Projection of reduction of the cutter length along } Z \text {-axis } \\
\text { direction }\end{array}$ \\
\hline $\mathrm{L}$ & Length of the overhanging part of the cutter \\
\hline $\mathrm{d} f_{\mathrm{a}}$ & Axial force \\
\hline $\mathrm{d} f_{\mathrm{r}}$ & Radial force \\
\hline $\mathrm{d} f_{t}$ & Tangential force \\
\hline$O_{W} X_{W} Y_{W} Z_{W}$ & Workpiece coordinate system \\
\hline$O_{L} X_{L} Y_{L} Z_{L}$ & Cutter coordinate system \\
\hline$n(z)$ & Normal vector \\
\hline$h$ & Undeformed chip thickness \\
\hline$k_{r}, k_{t}, k_{a}$ & Undeformed chip width \\
\hline & \\
\hline & \\
\hline
\end{tabular}

\section{Declarations}

a. Funding

This work was supported by National Natural Science Foundation of China under Grant No. 52005201.

b. Conflicts of interest/Competing interests 
The authors have no relevant financial or non-financial interests to disclose.

The authors have no conflicts of interest to declare that are relevant to the content of this article.

All authors certify that they have no affiliations with or involvement in any organization or entity with any financial interest or non-financial interest in the subject matter or materials discussed in this manuscript.

c. Availability of data and material

The measuring data in our paper are available from the corresponding author by request, and other related materials can also be obtained from the corresponding author.

d. Code availability

The code for cutting force model during the study are available from the corresponding author by request.

e. Ethics approval

Not applicable.

f. Consent to participate

All authors and facilitators have certified their participation in this work.

g. Consent for publication

All authors certify that they consent to publish the article. The article is the author's original work and has not been published in advance or considered for publication elsewhere.

h. Authors' contributions

Xianyin Duan and Lantao Li proposed the article's innovative thinking, derived the core formula of the article, and completed the English writing of the article. Chen Chen and Fangyu Peng putted forward many constructive Suggestions for the writing of the whole article, while Zerun Zhu putted forward some constructive Suggestions for the experimental part. Sheng Yu accomplished some parts of experimental validations.

\section{References}

1. Martellotti M E. An analysis of the milling process. trans. ASME, 63(2): 677-700

2. Malekian M, Mostofa M G, Park S S, et al (2012) Modeling of minimum uncut chip thickness in micro machining of aluminum. Journal of Materials Processing Technology, 212(3):553-559.

3. Budak E, Ozturk E, Tunc L T (2009) Modeling and simulation of 5-axis milling processes. CIRP Annals - Manufacturing Technology, 58(1):347-350.

4. Xuewei Z, Tianbiao Y, Ji Z (2020) An analytical approach on stochastic model for cutting force prediction in milling ceramic matrix composites. International Journal of Mechanical Sciences, 168.

5. Qinghua S, Zhanqiang L, et al (2019) A generalized cutting force model for five-axis milling processes. Journal of Engineering Manufacture, 233(1).

6. Lin Z, Ben D, Fangyu P, et al (2020) Semi-analytic modelling of cutting forces in micro ball-end milling of NAK80 steel with wear-varying cutting edge and associated nonlinear process characteristics. International Journal of Mechanical Sciences, 169.

7. Hui W, Yingbin H, et al (2019) A mechanistic model on feeding-directional cutting force in surface grinding of CFRP composites using rotary ultrasonic machining with horizontal ultrasonic vibration. International Journal of Mechanical Sciences, 155. 
8. Salehi M, Schmitz T L, Copenhaver R, et al (2019) Probabilistic sequential prediction of cutting force using Kienzle model in orthogonal turning process. ASME Journal of Manufacturing Science and Engineering, 141(1).

9. John M, William A, Anthony G (2019) Analytical and experimental investigations of the enhanced mechanical response of cutting deflection compared to progressive folding in AA6061 energy dissipation devices. International Journal of Mechanical Sciences, 151:808-827.

10. Zhoulong L, Limin Z (2016) Mechanistic Modeling of Five-Axis Machining with a Flat End Mill Considering Bottom Edge Cutting Effect. Journal of manufacturing science and engineering: Transactions of the ASME, 138(11):111012.

11. Jian W, Kejia Z, Cheng H, Han D (2020) A PSO-based semi-analytical force prediction model for chamfered carbide tools considering different material flow state caused by edge geometry. International Journal of Mechanical Sciences, 169.

12. Lexiang W, Yan H, Yulin W, et al (2020) Analytical modeling of material removal mechanism in dry whirling milling process considering geometry, kinematics and mechanics. International Journal of Mechanical Sciences, 172.

13. Ozturk E, Tunc L T, Budak E (2009) Investigation of lead and tilt angle effects in 5-axis ball-end milling processes. International Journal of Machine Tools and Manufacture, 49(14):1053-1062.

14. Lazoglu I, Boz Y, Erdim H (2011) Five-axis milling mechanics for complex free form surfaces. CIRP Annals - Manufacturing Technology, 60(1):117-120.

15. Tuysuz O, Altintas Y, Feng H Y (2013) Prediction of cutting forces in three and five-axis ballend milling with tool indentation effect. International Journal of Machine Tools \& Manufacture, 66:66-81.

16. Wojciechowski. S, Matuszak. M, Powałka. B, et al (2019) Prediction of cutting forces during micro end milling considering chip thickness accumulation. International Journal of Machine Tools and Manufacture, 147.

17. Dongming G, Fei R, Yuwen S (2010) An Approach to Modeling Cutting Forces in Five-Axis Ball-End Milling of Curved Geometries Based on Tool Motion Analysis. Journal of Manufacturing Science and Engineering, 132(8).

18. Niu J, Ding Y, Geng Z, et al (2018) Patterns of regenerative milling chatter under joint influences of cutting parameters, tool geometries, and runout. ASME Journal of Manufacturing Science and Engineering, 140(12).

19. Wei Z C, Guo M L, Wang M J, et al (2019) Prediction of cutting force of ball-end mill for pencilcut machining. The International Journal of Advanced Manufacturing Technology,100(1).

20. Wei Z C, Guo M L, Wang M J, et al (2018) Prediction of cutting force in five-axis flat-end milling. The International Journal of Advanced Manufacturing Technology, 96(1).

21. Wei Z C, Guo M L, Wang M J, et al (2018) Force predictive model for five-axis ball end milling of sculptured surface. The International Journal of Advanced Manufacturing Technology, 98(58):1367-1377.

22. Zhu K, Zhang Y (2017) Modeling of the instantaneous milling force per tooth with tool run-out effect in high speed ball-end milling. International Journal of Machine Tools and Manufacture, 118119:37-48. 
23. Xiubing J, Rongyu L, Yun C, Yanling T, Huaizhong L (2020) Modelling and experimental analysis of the effects of run out, minimum chip thickness and elastic recovery on the cutting force in micro-end-milling. International Journal of Mechanical Sciences, 176.

24. Zhang X, Zhang J, Xiaowei Z, et al (2017) Tool orientation optimization of 5-axis ball-end milling based on an accurate cutter/workpiece engagement model. CIRP Journal of Manufacturing Science and Technology,106-116.

25. Zhoulong L, Limin Z (2018) An accurate method for determining cutter-workpiece engagements in five-axis milling with a general tool considering cutter runout. ASME Journal of Manufacturing Science and Engineering, 140(2).

26. Xianyin D, Fangyu P, Rong Y, et al (2016) Estimation of Cutter Deflection Based on Study of Cutting Force and Static Flexibility. Journal of Manufacturing Science \& Engineering Transactions of the ASME, 138.

27. Mohsen S, Behrooz A, Mohsen H (2016) Tool Deflection Error of Three Axis Computer Numerical Control Milling Machines, Monitoring and Minimizing by a Virtual Machining System. Journal of Manufacturing Science \& Engineering Transactions of the ASME, 138(8):081005.

28. Zeroudi N, Fontaine M (2015) Prediction of tool deflection and tool path compensation in ballend milling. Journal of Intelligent Manufacturing, 26(3):425-445.

29. Mamedov A, Elk S, Lazoglu I (2015) Instantaneous tool deflection model for micro milling. International Journal of Advanced Manufacturing Technology, 79(5-8):769-777.

30. Huo D, Chen W, Teng X, et al (2017) Modeling the Influence of Tool Deflection on Cutting Force and Surface Generation in Micro-Milling. Micromachines, 8(6):188.

31. Zhang X, Yu T, Wang W (2017) Prediction of cutting forces and instantaneous tool deflection in micro end milling by considering tool run-out. International Journal of Mechanical Sciences, 136:124-133.

32. Altintas Y, Tuysuz O, Habibi M, et al (2018) Virtual compensation of deflection errors in ball end milling of flexible blades. Cirp Annals, 0007-8506.

33. Kim G M, Kim B H, Chu C N (2003) Estimation of cutter deflection and form error in ball-end milling processes. International Journal of Machine Tools \& Manufacture, 43(9):917-924.

34. Xianyin Du, Fangyu P, et al (2015) Experimental study of the effect of tool orientation on cutter deflection in five-axis filleted end dry milling of ultrahigh-strength steel. The International Journal of Advanced Manufacturing Technology, 81(1):653-666.

35. Rodríguez P, Labarga J E (2015) Tool deflection model for micro milling processes. The International Journal of Advanced Manufacturing Technology, 76(1-4):199-207.

36. Xianyin D, Fangyu P, Zerun Z, et al (2019) Cutting edge element modeling-based cutterworkpiece engagement determination and cutting force prediction in five-axis milling. The International Journal of Advanced Manufacturing Technology, 00170-018-3082-7. 